\title{
Barriers to diaphragm use: the views of advanced practice nurses
}

\author{
Andrzej Kulczycki, Haiyan Qu, Penelope M Bosarge, Richard M Shewchuk
}

\begin{abstract}
Background and methodology Women have used the contraceptive diaphragm for decades. Although use has recently declined, the diaphragm may find a new role in STI/HIV and dual-prevention programmes when microbicides become available. We developed a questionnaire to examine seven provider issues identified as possible barriers to diaphragm use among advanced practice nurses (APNs) specialising in women's health. The perceived degree to which each issue represented a barrier was examined. Non-parametric correlations were calculated between diaphragm fitting history, demographic and practice characteristics, and the response ratings for each issue.
\end{abstract}

Results Responses were analysed for 204 APNs who averaged 15 years' experience in women's health care; $87 \%$ had fitted a diaphragm at least once, but $40 \%$ had not prescribed one in the past year. The degree to which each issue was perceived as a barrier varied. Based on respondents' ratings of a 'more than moderate barrier, diaphragm non-promotion by women's health providers, effectiveness doubts, unfamiliarity and lack of access to educational materials were more often perceived as impeding diaphragm use. Other results indicated that APNs with recent diaphragm fitting history perceived five of the seven issues to be less of a barrier: non-promotion by women's health providers, lack of access to educational materials and to a fitting set, unfamiliarity, and inadequate reimbursement.

Discussion and conclusions Formulation of successful strategies to reintroduce the diaphragm will depend on better identification and understanding of providerperceived barriers. This paper offers new insights about such barriers and guidance for the development of strategies for diaphragm reintroduction.

Keywords barrier contraception, diaphragm, nurses, practice patterns, provider barriers

J Fam Plann Reprod Health Care 2010; 36(2): 79-82

(Accepted 6 February 2010)

\section{Introduction}

High rates of unintended pregnancies and sexually transmitted infections (STIs) underscore the urgent need to improve barrier contraceptive options and use. Femalecontrolled methods are particularly vital because women suffer disproportionately from these twin burdens and cannot control condom use. Diaphragms, long used for contraception, are now being reconsidered for dual-method use and specifically as an intervention for limiting sexual transmission of bacterial STIs and HIV, especially when used with a microbicide. ${ }^{1-6}$

However, diaphragm use has fallen and, along with all other vaginal barrier methods, now accounts for less than $1 \%$ of all contraceptive use globally. ${ }^{7}$ Many clinicians appear unwilling to recommend the diaphragm, despite its excellent safety profile and high acceptability reported by current method users in multiple countries. ${ }^{8-14}$ This study assesses potential barriers to diaphragm use as perceived by providers. Such barriers must be identified and better

Program in Maternal and Child Health, Department of Health Care Organization \& Policy, University of Alabama at

Birmingham, Birmingham, AL, USA

Andrzej Kulczycki, PhD, Associate Professor

Department of Health Services Administration, School of Health Professions, University of Alabama at Birmingham,

Birmingham, AL, USA

Haiyan Qu, PhD, Research Assistant Professor

Richard M Shewchuk, PhD, Professor

Women's Health Nurse Practitioner Option, UAB School of Nursing, University of Alabama at Birmingham, Birmingham, AL, USA

Penelope M Bosarge, MSN, FAANP, Manager and Instructor

Correspondence to: Dr Andrzej Kulczycki, Department of Health Care Organization \& Policy, Maternal and Child Health

Concentration, University of Alabama at Birmingham, 320 Ryals School of Public Health, 1665 University Boulevard, Birmingham, AL 35294-0022, USA. E-mail: andrzej@uab.edu

\section{Key message points}

- It is important to understand providers' perceptions of the diaphragm in preparation for possible method reintroduction for STI/HIV and dual prevention.

- From the provider perspective, the strongest impediments to diaphragm use among the seven issues examined included lack of promotion by providers, doubts about its effectiveness, unfamiliarity and inadequate access to educational materials.

- Diaphragm promotion and better education of health care providers, including training in diaphragm fitting, are needed to increase its use.

understood so that they can be overcome, ${ }^{15}$ especially as the diaphragm may have a large future potential in dualprotection programmes.

\section{Methods}

We assessed the relative significance attached by advanced practice nurses (APNs) to a range of potential barriers to diaphragm use. We developed a survey questionnaire based on a critical review of articles on the diaphragm and provider-related questionnaires on family planning; interviews with 22 reproductive health care practitioners in Birmingham, AL, USA; and expert panels with authoritative diaphragm providers and researchers. ${ }^{16,17} \mathrm{~A}$ pilot questionnaire was tested with 78 nurses and nurse practitioners working in family planning clinics for the Alabama Department of Public Health. A revised questionnaire was administered to the $450 \mathrm{APNs}$ (including nurse practitioners and certified nurse-midwives) who attended the 2006 annual conference of the US National Association of Nurse Practitioners in Women's Health (NPWH). These are frontline reproductive health care providers engaged in the practice of prescribing contraceptives.

Respondents were asked to evaluate the extent to which they considered each of seven provider issues as barriers to diaphragm use. These included diaphragm counselling 
Table 1 Sample descriptive statistics for age, practice and fitting history characteristics ( $n=204$ respondents)

\begin{tabular}{|c|c|c|c|c|c|c|}
\hline \multirow[t]{2}{*}{ Characteristic } & \multirow[t]{2}{*}{ Minimum } & \multicolumn{3}{|c|}{ Quartiles } & \multirow[t]{2}{*}{ Maximum } & \multirow[t]{2}{*}{$\%$} \\
\hline & & I & II & III & & \\
\hline $\begin{array}{l}\text { Age (years) } \\
\text { Years of practice in women's health care }(n) \\
\text { Family planning patients seen per week }(n)\end{array}$ & $\begin{array}{r}24.0 \\
0.0 \\
0.0\end{array}$ & $\begin{array}{r}40.0 \\
7.0 \\
15.0\end{array}$ & $\begin{array}{l}50.0 \\
14.0 \\
25.0\end{array}$ & $\begin{array}{l}55.0 \\
23.0 \\
42.0\end{array}$ & $\begin{array}{r}75.0 \\
37.0 \\
250.0\end{array}$ & \\
\hline $\begin{array}{l}\text { Diaphragm fitting history }(\%) \\
\text { Never fitted } \\
\text { Yes, but over } 1 \text { year ago } \\
\text { Yes, within the past } 12 \text { months }\end{array}$ & & & & & & $\begin{array}{l}13.5 \\
26.6 \\
59.9\end{array}$ \\
\hline
\end{tabular}

perceived to be too time-consuming, provider unfamiliarity with the diaphragm, providers lack access to a fitting set, providers doubt the effectiveness of the diaphragm, providers in women's health do not promote it, providers are inadequately reimbursed for this method, and providers lack access to educational materials. Each barrier was rated on a five-point scale $(1=$ not a barrier; $3=$ moderate barrier; $5=$ very strong barrier). Data were also collected regarding personal and professional practice characteristics including age and sex, years of practice in women's health care, the number of family planning patients seen per week, and experience of fitting a diaphragm (measured both in terms of having ever fitted a diaphragm and having fitted one in the past year). Diaphragm fitting history was recoded to create one threelevel variable: never fitted, fitted but over 1 year ago, and fitted in the past year.

Aggregate perceptions of these issues were explored, along with sample background demographic and practice characteristics. Given the non-continuous nature of the data for our barrier measures, Spearman's rho correlations were computed between the ordered categories of perceived barrier ratings (using the original five-point response scale) and provider demographic, practice and fitting characteristics. Spearman's rho is a non-parametric measure of statistical association between two variables, giving values between -1 and +1 , such that zero indicates no association and the higher the absolute value of rho, the stronger the relationship. Negative values for rho describe inverse associations (i.e. the higher the value of the first variable, the lower the value tends to be on the other variable). Data analysis was undertaken using Statistical Package for the Social Sciences (SPSS) statistical software (SPSS Inc., Chicago, IL, USA).

\section{Ethical approval}

The institutional review boards of the University of Alabama at Birmingham (UAB) and the Alabama Department of Public Health, as well as the NPWH board of directors, approved the study and the survey instrument prior to its field application.

\section{Results}

Ten of the 214 returned survey questionnaires had missing data for some of the questions studied, such that responses were analysed for $45 \%$ of all forms distributed. Survey respondents were from 189 zip code areas of the USA, indicating a very good geographic representation (data not shown). Respondents were all female with a mean age of 48 years and 15 years' experience in women's health care; $54 \%$

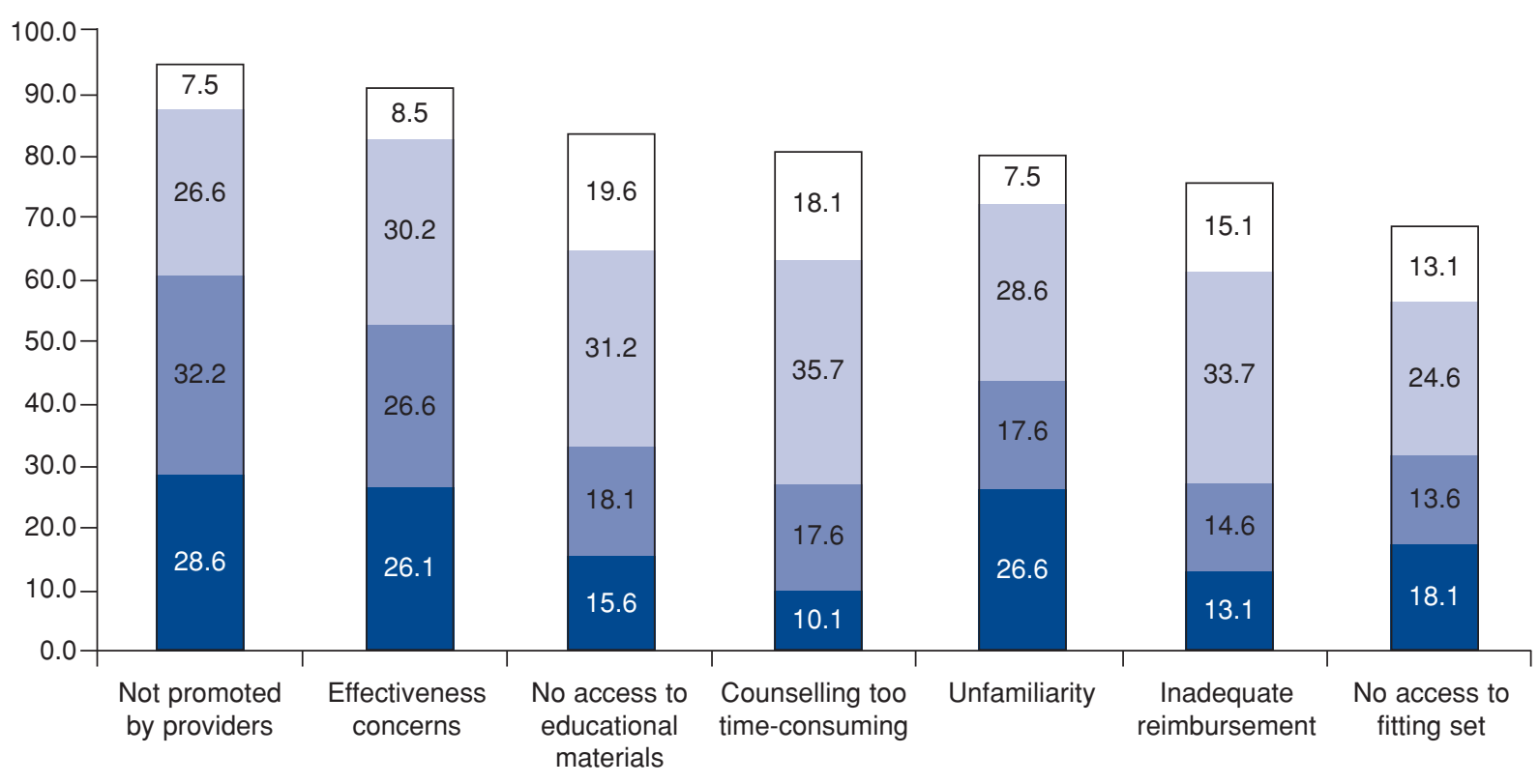

Perceived strength of barrier:*

Relatively minor

Moderate

Relatively strong

Very strong

Figure 1 Percentage distribution of responses regarding perception of provider issues as barriers to diaphragm use, in order of total frequency of 'barrier judgements' ( $n=204$ respondents). Responses of 'not a barrier' are not plotted but would complete bars up to $100 \%$. *See explanation of ratings in Methods section. 
Table 2 Spearman's rho correlations between issues perceived by advanced practice nurses as barriers to diaphragm use and provider characteristics

\begin{tabular}{|c|c|c|c|c|}
\hline \multirow[t]{2}{*}{ Perceived barrier } & \multicolumn{4}{|c|}{ Provider characteristics } \\
\hline & Age & $\begin{array}{l}\text { Years of practice } \\
\text { in women's health } \\
\text { care }\end{array}$ & $\begin{array}{l}\text { Family planning } \\
\text { patients seen per } \\
\text { week }\end{array}$ & $\begin{array}{l}\text { Diaphragm fitting } \\
\text { history }\end{array}$ \\
\hline $\begin{array}{l}\text { Not promoted by providers } \\
\text { Effectiveness concerns } \\
\text { No access to educational materials } \\
\text { Counselling too time-consuming } \\
\text { Unfamiliarity } \\
\text { Inadequate reimbursement } \\
\text { No access to fitting set }\end{array}$ & $\begin{array}{rr}0.0 & (-0.2,0.1) \\
-0.1^{*} & (-0.3,0.0) \\
-0.1 & (-0.2,0.1) \\
0.1 & (0.0,0.3) \\
0.1 & (-0.1,0.2) \\
0.1 & (-0.1,0.2) \\
-0.1 & (-0.2,0.1)\end{array}$ & $\begin{aligned} &-0.1(-0.3,0.0) \\
&-0.1(-0.2,0.1) \\
&-0.1(-0.3,0.0) \\
& 0.0(-0.1,0.2) \\
& 0.0(-0.1,0.1) \\
& 0.0(-0.1,0.2) \\
& 0.0(-0.2,0.1)\end{aligned}$ & $\begin{array}{r}0.0(-0.2,0.1) \\
0.0(-0.1,0.2) \\
-0.2^{*}(-0.2,0.0) \\
0.0(-0.1,0.2) \\
-0.1(-0.2,0.1) \\
-0.1(-0.2,0.0) \\
-0.2^{*}(-0.3,0.0)\end{array}$ & $\begin{array}{ll}-0.3^{* *} & (-0.4,-0.2) \\
-0.1^{* *} & (-0.2,0.0) \\
-0.3^{* *} & (-0.4,-0.1) \\
-0.1^{* *}(-0.3,0.0) \\
-0.2^{* *}(-0.4,-0.1) \\
-0.2^{* *}(-0.3,-0.1) \\
-0.3^{* *}(-0.4,-0.2)\end{array}$ \\
\hline
\end{tabular}

The $95 \%$ confidence intervals are given in parentheses. ${ }^{*}$ Correlation is significant at the 0.05 level (two-tailed). ${ }^{*}$ Correlation is significant at the 0.01 level (two-tailed).

had a weekly caseload of at least 25 family planning patients. In addition, $87 \%$ of respondents had fitted a patient with a diaphragm at least once during their career, but among these APNs, $31 \%$ had not done so in the past year. Overall sample descriptive characteristics are presented in Table 1.

The distribution of response ratings for the sample is presented in Figure 1, with the overall heights of the columns showing the percentage of respondents who perceived a particular item as posing some degree of barrier to recommending diaphragm use. Over $90 \%$ of respondents viewed the issues of not being promoted by providers and effectiveness concerns as barriers to diaphragm use. High proportions of APNs (over 80\%) also endorsed lack of access to educational materials, the potentially time-consuming nature of diaphragm counselling, and provider unfamiliarity as being barriers. Fewer APNs cited lack of access to a diaphragm fitting set than any other issue; however, over two-thirds (69\%) of respondents still considered this issue a barrier.

The first two slices of the stacked bars shown in Figure 1 also indicate the proportion of respondents who rated each of the issues as 'more than moderate barriers' (response categories 4 or 5). On this basis, the ordering of the issues as barriers changes modestly. The first two issues remained dominant concerns in that they were cited by over half the sample; additionally, $44 \%$ of APNs considered provider unfamiliarity as more than a moderate barrier. In contrast, only $28 \%$ of APNs ascribed similar weight to the issues of time spent on diaphragm counselling and inadequate reimbursement.

Non-parametric correlations in Table 2 show some statistically significant inverse ordinal associations between the degree of perception as barrier and provider age/experience. The strongest associations were with fitting history, such that for five of the seven issues (not promoted by providers, no access to educational materials, no access to fitting set, unfamiliarity, and inadequate reimbursement), greater perception as barrier was reported by those with non-recent or no experience of fitting a diaphragm (all $p<0.01$ ). No access to a fitting set or educational materials were also more likely to be seen as barriers by those with lower caseloads (both $p<0.05$ ). Finally, effectiveness concerns were more often perceived as a barrier by younger respondents $(p<0.05)$. The potentially time-consuming nature of diaphragm counselling was the only item not to show any statistically significant associations with the provider characteristics. Among these characteristics, only 'years of practice' showed no significant association with any of the perceived barriers to diaphragm use.

\section{Discussion}

Our understanding of provider attitudes regarding the diaphragm is rudimentary. To the best of the authors' knowledge, this is the first systematic enquiry into possible barriers to diaphragm use. The analysis enables several inferences to be drawn about the relative importance of issues that interventions would need to address to improve diaphragm use. APNs rated diaphragm non-promotion, unfamiliarity, effectiveness concerns, and lack of access to educational materials as 'more than moderate' barriers to its use. The needs for better diaphragm marketing, provider-endorsement and training are underscored by the finding that at least every second respondent rated the issues of non-promotion and effectiveness doubts as "more than moderate' barriers. The issue of inadequate access to educational materials cuts across these concerns and needs greater attention.

Effectiveness concerns are unsurprising since, in general use, barrier methods provide only moderate contraceptive effectiveness. ${ }^{18}$ These concerns were most often perceived as a barrier by younger respondents. Without remedial action, natural 'ageing' of the workforce will exacerbate this pattern as there will be fewer providers amenable to the diaphragm. The same holds true for items correlated with fitting history, because this experience will be lost altogether as the workforce ages. Conversely, perhaps the easiest problem to fix concerns lack of access to a diaphragm fitting set, which is essentially a logistical issue. Closer examination of the responses shows that, not surprisingly, APNs with more recent experience of having fitted a diaphragm had fewer reservations about each of these issues compared to those with less fitting experience. Respondents who endorsed an issue more strongly tended to also indicate that they were less likely to have ever fitted a patient with a diaphragm.

Our study has some limitations. First, individuals who attend nurses' conferences may not be fully representative of their profession. They may, for example, be somewhat more active in their professional organisation and interested in updating their skills than the average rankand-file nurse. As noted above, however, our sample comprised geographically dispersed respondents from across the USA. They were also representative of the national NPWH membership in several other characteristics for which data are known. For example, survey respondents were almost undifferentiated in terms of working in family planning and community health clinics (23\% vs $21 \%) .{ }^{16}$

Second, survey respondents were APNs and although broadly representative of their profession, they may not be strictly comparable to regular nurses because they may 
have had additional training and certification. Thus, these observations may not be entirely replicated in other countries, including the UK where much family planning care is provided by general nurses. Conversely, APNs are registered nurses with additional specialised education, and nurses in the UK and the USA working in this field most likely see similar problems and deal with comparable issues. Moreover, the seven potential barriers identified were generated by nurses (and by a smaller number of nurse practitioners) in our formative research. And while the distributions may vary across health care plans and programmes, differences may also be attributable to the extent to which professional associations endorse the diaphragm, how it is being currently used in practice, the extent of educational materials available and used. Nonetheless, we feel it is of value to see how these nurseidentified barriers relate to providers' practice of recommending the diaphragm to their patients. Thus, although it is possible that the differences may change, these nurse-generated issues do not change.

Third, although a larger response rate and sample size would have been ideal, our sample size was sufficiently powerful to identify significant associations between how individuals rated each issue as a potential barrier to diaphragm use and their age, practice and diaphragm fitting history characteristics. Moreover, our response rate is not significantly different from the average of most surveys conducted with various types of organisations. ${ }^{19}$ As noted above, our analysis did not indicate any obvious sign of selection bias. It is possible that there are other relevant issues that may be considered as barriers to diaphragm use. However, we had conducted extensive formative work to develop our survey questions on the topic and very few other issues surfaced in response to an ancillary openended question that asked respondents to identify any additional relevant concerns.

\section{Conclusions}

Diaphragm use has declined in recent decades, but may become a more attractive option as new, improved designs become available which, if used in combination with microbicides that are being developed, will reduce risk of STI/HIV transmission. ${ }^{1-5,20-22}$ Accordingly, greater efforts are needed now to prepare the way forward to reintroducing the diaphragm. Registered nurses, including APNs, are well suited for facilitating method adoption in appropriate cases. To the best of our knowledge, this is the first systematic study to assess provider barriers to diaphragm use. Better identification and understanding of such barriers will lead to the formulation of appropriate strategies to increase the likelihood that the diaphragm could be used in practice.

\section{Statements on funding and competing interests}

Funding The study was funded by the Lister Hill Center for Health Policy, University of Alabama at Birmingham, AL, USA

Competing interests None identified.

\section{References}

1 Harvey SM. A new look at an old method: the diaphragm. Perspect Sex Reprod Health 2003; 35: 270-273.

2 Narrigan D. Women's barrier contraceptive methods: poised for change. J Midwifery Womens Health. 2006; 51: 478-485.

3 Padian NS, Buvé A, Balkus J, Serwadda D, Cates W.
Biomedical interventions to prevent HIV infection: evidence, challenges, and way forward. Lancet 2008; 372: 585-599.

4 Barnhart KT, Rosenberg MJ, MacKay HT, Blithe DL, Higgins J, Walsh $\mathrm{T}$, et al. Contraceptive efficacy of a novel spermicidal microbicide used with a diaphragm: a randomized controlled trial. Obstet Gynecol 2007; 110: 577-586.

5 Minnis AM, Padian NS. Effectiveness of female controlled barrier methods in preventing sexually transmitted infections and HIV: current evidence and future research directions. Sex Transm Infect 2005; 81: 193-200.

6 Ramjee G, van der Straten A, Chipato T, de Bruyn G, Blanchard K, Shiboski S, et al.; MIRA Team. The diaphragm and lubricant gel for prevention of cervical sexually transmitted infections: results of a randomized controlled trial. PLOS One 2008; 3: e3488.

7 United Nations Department of Economic and Social Affairs: Population Division. World Contraceptive Use 2009 (wall chart). http://www.un.org/esa/population/publications/ contraceptive2009/contraceptive2009.htm [Accessed 28 January 2010].

8 Di Giacomo do Lago T, Barbosa RM, Kalckmann S, Villela WV, Gohiman S. Acceptability of the diaphragm among low-income women in Sao Paulo, Brazil. Int Fam Plann Perspect 1995; 21: 114-118.

9 Maher JE, Harvey MS, Bird ST, Stevens VJ, Beckman LJ. Acceptability of the vaginal diaphragm among current users. Perspect Sex Reprod Health 2004; 36: 64-71.

10 Ortayli N, Bulut $A$, Nalbant $H$, Cottingham J. Is the diaphragm a viable option for women in Turkey? Int Fam Plann Perspect 2000; 26: 36-42.

11 Bulut A, Ortayli N, Ringheim K, Cottingham J, Farley TM, Peregoudov $\mathrm{A}$, et al. Assessing the acceptability, service delivery requirements, and use-effectiveness of the diaphragm in Colombia, Philippines, and Turkey. Contraception 2001, 63: 267-275.

12 Ravindran TKS, Rao SS. Is the diaphragm a suitable method of contraception for low-income women: a user perspectives study, Madras, India. In: Beyond Acceptability: Users Perspectives on Contraception. London, UK: Reproductive Health Matters for the World Health Organization, 1997.

13 Behets F, Norris Turner A, Van Damme K, Rabenja NL, Ravelomanana N, Zeller K, et al. Acceptability and feasibility of continuous diaphragm use among sex workers in Madagascar. Sex Transm Infect 2005; 81: 472-476.

14 Bird ST, Harvey, SM, Maher, J, Beckman, LJ. Acceptability of an existing, female-controlled contraceptive method that could potentially protect against HIV: a comparison of diaphragm users and other method users. Womens Health Issues 2004; 14: 85-93.

15 Welsh MJ, Stanbeck J, Shelton J. Access to modern contraception. Best Pract Res Clin Obstet Gynaecol 2006; 20: 323-338.

16 Kulczycki A, Bosarge, PM, Qu H, Shewchuk RM. New purpose, old method: NPs' perceptions of the diaphragm. Womens Health Care 2007; 6: 64-70.

17 Kulczycki A, Shewchuk RM. Using Internet-based nominal group technique meetings to identify provider strategies for increasing diaphragm use. J Fam Plann Reprod Health Care 2008; 34: 227-231.

18 Bosarge PM. Effectiveness of barrier methods for sexually transmitted infection prevention. In: Nelson AL, Woodward J (eds), Sexually Transmitted Diseases: A Practical Guide for Primary Care. Totowa, NJ: Humana Press, 2006; 305-319.

19 Baruch Y, Holtom BC. Survey response rate levels and trends in organizational research. Hum Relat 2008; 61: 1139-1160.

20 Coffey PS, Kilbourne-Brook M, Beksinska M, Thongkrajai E. Short-term acceptability of a single-size diaphragm among couples in South Africa and Thailand. J Fam Plann Reprod Health Care 2008; 34: 233-236.

21 Alliance for Microbicide Development. Mapping the Microbicide Effort. Silver Spring, MD: Alliance for Microbicide Development, 2007

22 Microbicide Trials Network. Fact Sheet: HPTN 035 at a Glance. http://www.mtnstopshiv.org/news/studies/hptn035/facts [Accessed 28 January 2010].

\section{Visit the Faculty Website at www.fsrh.org}

